\title{
Spatial and temporal changes analysis of air quality before and after the COVID-19 in Shandong Province, China
}

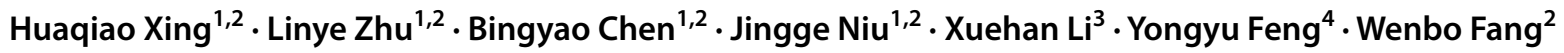

Received: 31 August 2021 / Accepted: 2 December 2021 / Published online: 27 January 2022

(c) The Author(s), under exclusive licence to Springer-Verlag GmbH Germany, part of Springer Nature 2022

\begin{abstract}
Due to the COVID-19 pandemic outbreak, the home quarantine policy was implemented to control the spread of the pandemic, which may have a positive impact on the improvement of air quality in China. In this study, Google Earth Engine (GEE) cloud computing platform was used to obtain $\mathrm{CO}, \mathrm{NO}_{2}, \mathrm{SO}_{2}$ and aerosol optical depth (AOD) data from December 2018-March 2019, December 2019-March 2020, and December 2020-March 2021 in Shandong Province. These data were used to study the spatial and temporal distribution of air quality changes in Shandong Province before and after the pandemic and to analyze the reasons for the changes. The results show that: (1) Compared with the same period, $\mathrm{CO}$ and $\mathrm{NO}_{2}$ showed a decreasing trend from December 2019 to March 2020, with an average total change of $4082.36 \mathrm{~mol} / \mathrm{m}^{2}$ and $167.25 \mathrm{~mol} /$ $\mathrm{m}^{2}$, and an average total change rate of $4.80 \%$ and $38.11 \%$, respectively. $\mathrm{SO}_{2}$ did not have a significant decrease. This is inextricably linked to the reduction of human travel production activities with the implementation of the home quarantine policy. (2) The spatial and temporal variation of AOD was similar to that of pollutants, but showed a significant increase in January 2020, with an average total amount increase of $1.69 \times 10^{7}$ up about 2.54\% from December 2019 to March 2020. This is attributed to urban heating and the reduction of pollutants such as $\mathrm{NO}_{\mathrm{x}}$. (3) Pollutants and AOD were significantly correlated with meteorological data (e.g., average temperature, average humidity, average wind speed, average precipitation, etc.). This study provides data support for atmospheric protection and air quality monitoring in Shandong Province, as well as theoretical basis and technical guidance for policy formulation and urban planning.
\end{abstract}

Keywords Air quality $\cdot$ COVID-19 $\cdot$ Google Earth Engine $\cdot$ Shandong Province

\section{Introduction}

With the improvement of urbanization and the increase of human activities, air pollution has become an increasingly serious problem (Azuma et al. 2020; Zhou et al. 2020; Song et al. 2021). Especially, many cities in northern winter have

Communicated by: H. Babaie.

Xuehan Li

15953169833@163.com

Yongyu Feng

fengyongyu@shandong.cn

Huaqiao Xing

xinghuaqiao@126.com

Linye Zhu

895916547@qq.com

Bingyao Chen

2362490545@qq.com

Jingge Niu

njgsdjzu@163.com
Wenbo Fang

webb@sdjzu.edu.cn

1 School of Surveying and Geo-informatics, Shandong Jianzhu University, Jinan, Shandong Province, China

2 The Key Laboratory of Digital Simulation in Spatial Design of Architecture and Urban-Rural, Shandong Provincial Education Department, Jinan, Shandong Province, China

3 University of Sydney, Sydney, Australia

4 Shandong Geographical Institute of Land Spatial Data and Remote Sensing Technology Center, Jinan, Shandong Province, China 
serious haze pollution, which affects human health and daily life. Scientific and effective exploration of air quality changes is of great importance for government decision making. Owing to the COVID-19 pandemic outbreak, the Chinese government adopted a home quarantine policy, which largely improved air quality in China. Therefore, this outbreak and lockdown period may be an excellent time to explore the driving factors of air quality change.

Many scholars have explored the impact of the pandemic lockdown initiative on air quality in China. The station data was frequently used to analyze the spatial and temporal changes of pollutant concentrations. For example, Zhu et al. (2020) studied the relationship between six air pollutants (i.e., $\mathrm{PM}_{2.5}, \mathrm{PM}_{10}, \mathrm{CO}, \mathrm{O}_{3}, \mathrm{NO}_{2}$ and $\mathrm{SO}_{2}$ ) and confirmed COVID-19 cases in 120 cities of China from January 23, 2020 to February 29, 2020 (Zhu et al. 2020). Yao et al. (2020) analyzed the association between $\mathrm{PM}_{2.5}$ and $\mathrm{PM}_{10}$ concentrations and COVID-19 case fatality rates in 49 cities of China from January 15, 2020 to March 22, 2020 (Yao et al. 2020). However, station data could not well demonstrate the spatial distribution of pollutant changes, and are not easily collected and obtained. The application of remote sensing data has increasingly developed into a key technical tool for global atmospheric environment monitoring compared with traditional air pollution monitoring technology. Remote sensing data can provide data support for air quality monitoring with certain accuracy and relatively easy access (Zhao et al. 2017; Asokan and Anitha 2019). For example, Prakash et al. (2021) used the GEE platform to obtain Sentinel-5P and MCD19A2 data for March and April 2019 and 2020 to assess the major pollutants in major Indian cities during the pandemic lockdown period (Prakash et al. 2021). Meng et al. (2021) obtained $\mathrm{CO}, \mathrm{NO}_{2}, \mathrm{O}_{3}$ and $\mathrm{SO}_{2}$ concentrations from January 23, 2020 to May 31, 2020 by Sentinel-5P data to exploit the non-linear relationship between annual and daily global air pollution concentrations and daily confirmed cases (Meng et al. 2021). Dutheil et al. (2020) compared $\mathrm{NO}_{2}$ concentrations in some regions of China from January-March 2019 and January-March 2020 by Sentinel-5P data (Dutheil et al. 2020). Ghasempur et al. (2021) explored the spatial and temporal distribution of $\mathrm{NO}_{2}$ and $\mathrm{SO}_{2}$ in Sentinel-5P data and AOD in MODIS data from January 2019 to September 2020 in Turkey through the GEE platform and discovered that Sentinel-5P data were strongly correlated with station data (Ghasempour et al. 2021). Zheng et al. (2019) used $\mathrm{NO}_{2}$ data from Sentinel-5P to explore the spatial and temporal characteristics and influencing factors of $\mathrm{NO}_{2}$ concentrations in mainland China from February 2018 to January 2019, where $\mathrm{NO}_{2}$ concentrations from Sentinel-5P were highly correlated with $\mathrm{NO}_{2}$ concentrations from urban surface monitoring $\left(\mathrm{p}<0.05, \mathrm{R}^{2}=0.72\right)$ (Zheng et al. 2019). In the above-mentioned studies, the pollutant data from Sentinel-5P data were employed to detect air quality changes with favorable effects and highly correlated with pollutant station data.

Therefore, this paper utilized the Google Earth Engine (GEE) platform to explore the air quality changes in different years during the same period of the pandemic outbreak and lockdown (i.e., December 2018 to March 2019, December 2019 to March 2020, December 2020 to March 2021). GEE (https://code.earthengine.google.com) is a free, cloud-based platform that allows for in-cloud data access, processing and management (Tamiminia et al. 2020). Its strength lies in the combination of petabyte-scale satellite imagery and geospatial datasets with planetary-scale analysis capabilities, allowing for easy analysis and mapping at the global level, with easy access to data and 'unlimited' and stable processing power (Hu et al. 2018; Chen et al. 2021). Furthermore, the driving factors of air quality changes before and after the COVID-19 outbreak were explored to investigate the sources influencing air quality change.

The contributions of this paper are as follows: (1) This study understands the changes in air pollution levels from the coexistence of multiple pollutants after the implementation of the COVID-19 home quarantine policy in Shandong Province. We used satellite remote sensing data and compared the three times of the non-pandemic period, the pandemic period, and the basic end of pandemic to explore the impact of pandemic on air quality from a relatively comprehensive perspective. (2) This study quantifies the relationship between meteorological observations and air pollution, and explores the extent to which industrial, daily life and other activities affect air pollution in Shandong Province. We examined a few spatial regression models for identifying meteorological factors as explanatory variables to explain air quality changes during the pandemic. The driving factors of air quality changes from economic and social statistics were discussed in depth from the perspectives of mobile sources, industrial sources, and domestic sources.

The objective of this study is to analyze the air quality in Shandong Province during the pandemic lockdown from the perspective of air pollution. The dynamic changes of air quality in Shandong Province were studied from a more comprehensive perspective by comparing the air quality with the non-pandemic period and the approximate end of the pandemic. Meanwhile, due to the complex influences of emissions and meteorology, the impacts of natural and anthropogenic factors on air quality changes were systematically and quantitatively analyzed to understand the reasons why serious air pollution was not avoided in previous years and to provide theoretical support for scientific and effective air pollution control in the future. 


\section{Data and methods}

\section{Study area}

The study area was Shandong Province, located in the Bohai Sea region of eastern China (see Fig. 1), between $34^{\circ} 22.9^{\prime}-38^{\circ} 24.01^{\prime} \mathrm{N}$ and $114^{\circ} 47.5^{\prime}-122^{\circ} 42.3^{\prime} \mathrm{E}$ (Zhang et al. 2016). Shandong province has a large population, with a resident population of 100,702,100 at the end of 2019. Shandong Province is one of the most economically developed provinces in China, with a gross domestic product of 7,312.90 billion yuan in 2020 .

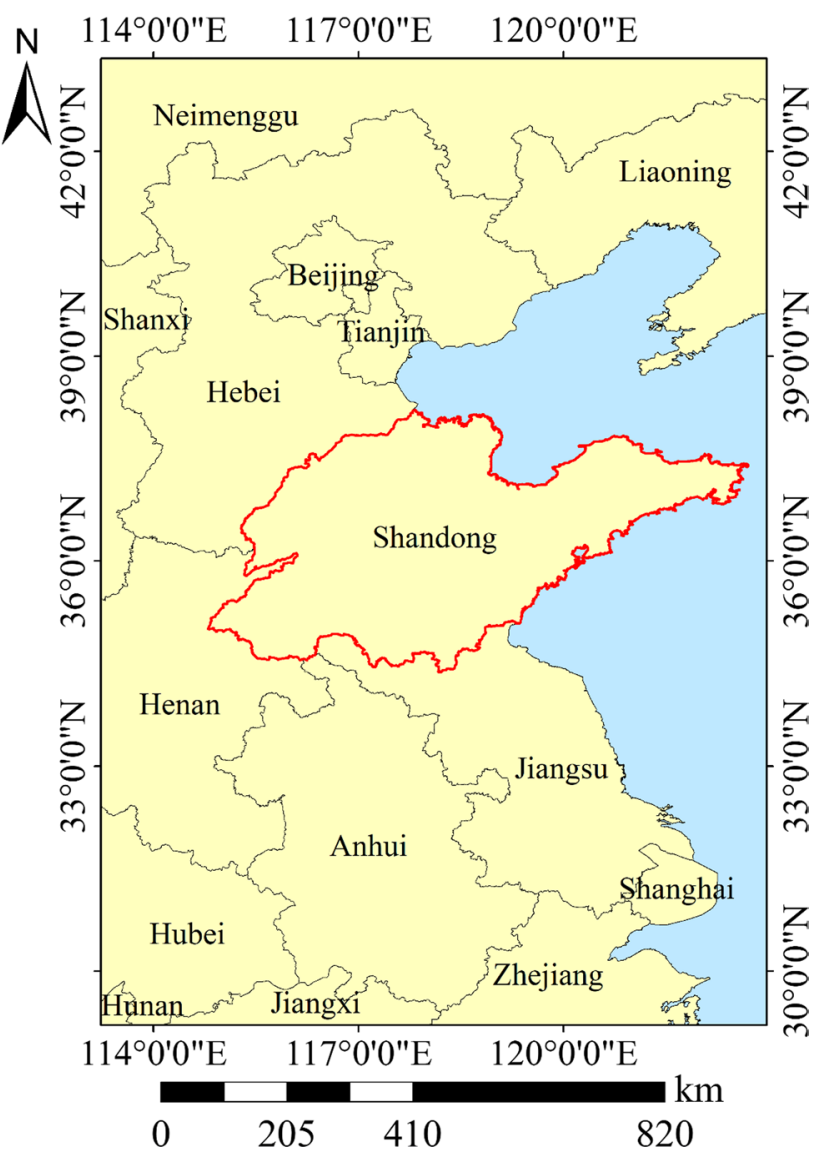

\section{Datasets}

Sentinel-5P is a global atmospheric pollution monitoring satellite launched by European Space Agency on October 13, 2017. The satellite carries tropospheric monitoring instruments and is capable of effectively observing trace gas constituents in the global atmosphere, including important indicators closely related to anthropogenic activities, e.g., $\mathrm{NO}_{2}, \mathrm{O}_{3}, \mathrm{SO}_{2}, \mathrm{CH}_{4}$ and $\mathrm{CO}$ (Vîrghileanu et al. 2020; Schneider et al. 2021). Aerosol optical depth (AOD) from moderate resolution imaging spectrometer (MODIS) data and Sentinel-5P air pollution data were acquired from the GEE platform (see Table 1). The time intervals for the study data were December 2018 to March 2019 (referred to as Period 1), December 2019 to March 2020 (referred to as Period 2), and December 2020 to March 2021 (referred to as Period 3). In addition, the factors affecting the changes in air quality before and after the COVID-19 pandemic were analyzed using meteorological station data from major cities in Shandong Province and statistical data from the National Bureau of Statistics. Among them, meteorological station data (e.g., average temperature, average humidity, average wind speed, etc.) were used as natural factors, and statistical data (e.g., industrial value added, cement, thermal power, gasoline, road passenger volume, natural gas, and gas, etc.) were used as anthropogenic factors.

\section{Methods}

\section{Acquisition of pollution data using GEE}

The GEE platform is widely used in many large-scale, long time series remote sensing applications (Mandal et al. 2018; Dlamini and Xulu 2019). In this study, all data acquisition and processing steps were performed online on the GEE platform using code. The original Sentinel-5P Level 2 (L2) data was time-graded, not latitude/longitude graded. To be able to incorporate the data into GEE platform, each Sentinel-5P L2 product was converted to Level 3 (L3) using the bin_spatial operation of the harpconvert tool (Gorelick et al. 2017). The source data was filtered to remove pixels with Quality Assurance (QA) values less than $75 \%$ for $\mathrm{NO}_{2}$ and $50 \%$ for $\mathrm{CO}$ (Butz et al. 2012). Finally, $\mathrm{NO}_{2}, \mathrm{SO}_{2}, \mathrm{CO}$, and $\mathrm{AOD}$ data

Fig. 1 Study area location map

Table 1 Description of datasets involved in the study

\begin{tabular}{llllll}
\hline Datasets & Sensor & Study interval & Units & Spatial resolution & Image collection ID \\
\hline $\mathrm{NO}_{2}$ & Sentinel-5P & $2018 / 12 / 01-2019 / 03 / 31$ & $\mathrm{~mol} / \mathrm{m}^{2}$ & 0.01 arc degrees & COPERNICUS/S5P/NRTI/L3_NO2 \\
$\mathrm{SO}_{2}$ & Sentinel-5P & $2019 / 12 / 01-2020 / 03 / 31$ & $\mathrm{~mol} / \mathrm{m}^{2}$ & $0.01 \mathrm{arc}$ degrees & COPERNICUS/S5P/NRTI/L3_SO2 \\
$\mathrm{CO}$ & Sentinel-5P & $2020 / 12 / 01-2021 / 03 / 16$ & $\mathrm{~mol} / \mathrm{m}^{2}$ & $0.01 \mathrm{arc} \mathrm{degrees}$ & COPERNICUS/S5P/NRTI/L3_CO \\
$\mathrm{AOD}$ & MODIS & & & $1 \mathrm{~km}$ & MODIS/006/MCD19A2_GRANULES
\end{tabular}


were obtained for different years from December to March and monthly averages were calculated using the GEE platform.

\section{Driving force analysis methods for Shandong Province}

In this study, Pearson correlation analysis was performed using Statistical Product and Service Solutions (SPSS 25) software (Shi and Shi 2020). Pearson correlation analysis was used to explore the degree of correlation between air quality and driving factors before and after the COVID-19 pandemic (Baeza and Paruelo 2020; Özelkan 2020).

In addition, spatial regression analysis was performed using GeoDa software, and ordinary least squares linear regression model (OLS), spatial lag model (SLM), and spatial error model (SEM) were compared to select the most appropriate method for constructing the air quality-meteorological model (Lina and Lixun 2019). The following are the mathematical expressions of the OLS model, SLM model and SEM model, respectively (Liu et al. 2015; Mollalo et al. 2020).

$Y=\beta_{0}+\beta X+\epsilon$

$Y=\beta_{0}+\rho \omega Y+\beta X+\epsilon$

$Y=\beta_{0}+\beta X+\varphi, \varphi=\lambda \omega \varphi+\epsilon$

where $Y$ is the dependent variable; $X$ is the independent variable; $\omega$ is the spatial adjacency matrix; $\beta_{0}$ is the constant intercept; $\beta$ is the independent variable coefficient; $\epsilon$ is the normally distributed error vector; $\rho$ and $\lambda$ are the spatial autoregressive and spatial autocorrelation coefficients, respectively. First-order Queen contiguity was used to establish the spatial relationship in Shandong province.

As shown in Fig. 2, the optimal regression model selection is judged by the Moran's I, Lagrange multiplier-lag (LM-lag), Lagrange multiplier-error (LM-error), goodness of fit $\left(\mathrm{R}^{2}\right)$, natural $\log$-likelihood function value ( $\left.\log \mathrm{L}\right)$, Akaike info criterion (AIC), etc. The model applicability is greater when the LM test passes with higher $\mathrm{R}^{2}$ and LogL values and lower AIC value (Lina and Lixun 2019).

The specific judgment steps are as follows: first run the OLS model, and if the Moran's I test is not significant, the OLS model is used as the optimal model. If the Moran's I test is significant, the LM-lag test and LM-error test are compared. If both LM-lag test and LM-error test are insignificant, the OLS model is used as the optimal model. If only the LM-lag test is significant, then the SLM model is used as the optimal model. If only the LM-error test is significant, the SEM model is used as the optimal model. If both LM-lag test and LM-error test are significant, the indicators of robust LM-lag test and robust LM-error test are compared. If the robust LM-lag test is significant, the SLM model is used as the optimal model. If the robust LM-error test is significant, the SEM model is used as the optimal model.

Fig. 2 Flow chart of optimal model selection

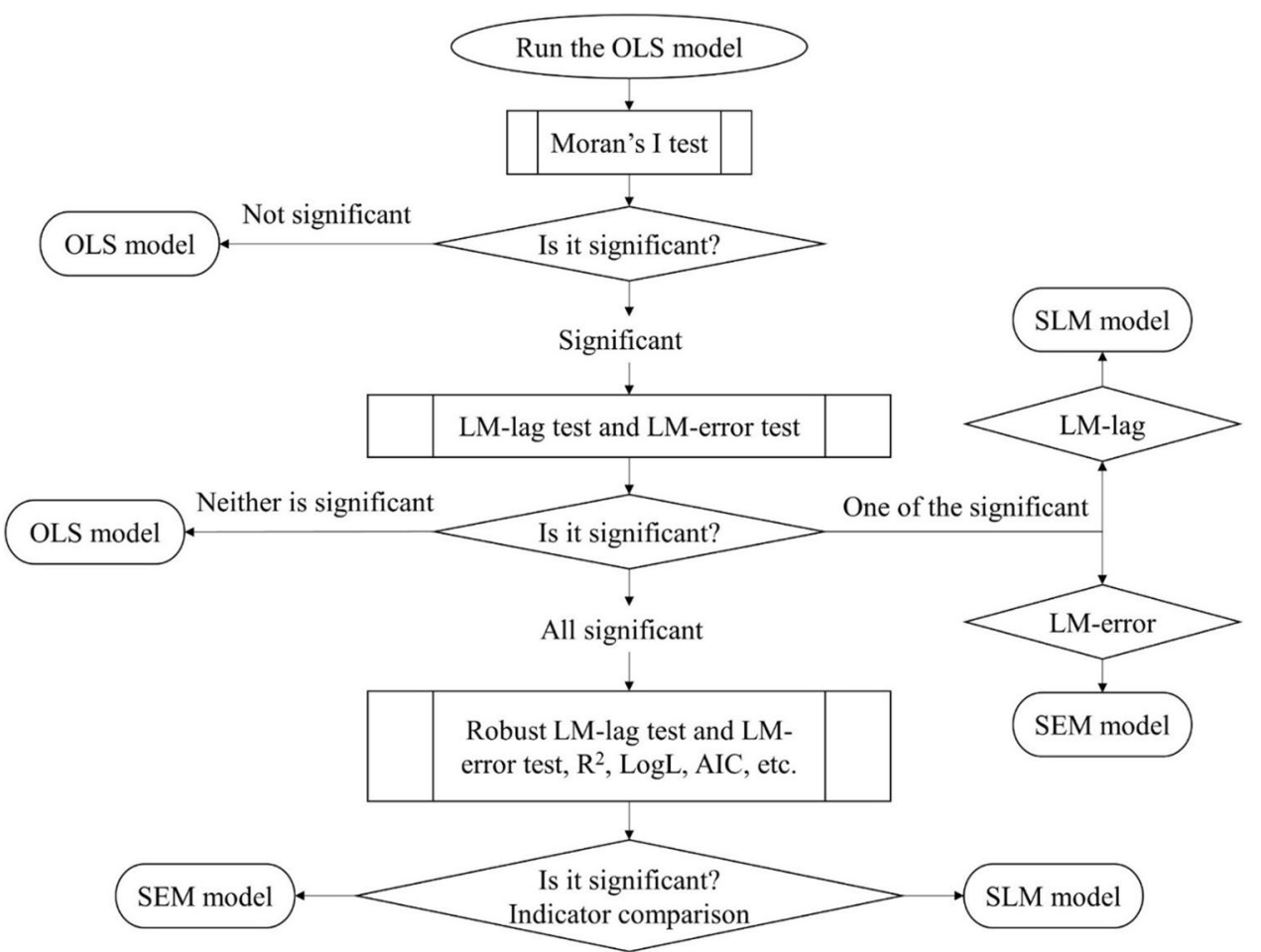




\section{Results and analysis}

\section{Spatial and temporal changes analysis of air quality in Shandong Province}

\section{Spatial and temporal analysis of pollutant concentrations}

According to the relevant literature (Xu et al. 2018), it is clear that the pollutant concentrations have a clear cyclical variation. Figures 3, 4 and 5 show the spatial and temporal distribution of $\mathrm{CO}$ concentration, $\mathrm{NO}_{2}$ concentration and $\mathrm{SO}_{2}$ concentration in Shandong Province, respectively, where $\mathrm{SO}_{2}$ data have missing data in December, so the average total amount of $\mathrm{SO}_{2}$ may be inaccurate. Figure 6 shows the average total change in pollutants between Period 1 and Period 2 and between Period 2 and Period 3.

From the monthly perspective, it can be seen that the concentration of these pollutants was higher from December to the following February. During the study period, the highest $\mathrm{CO}$ concentrations were observed in

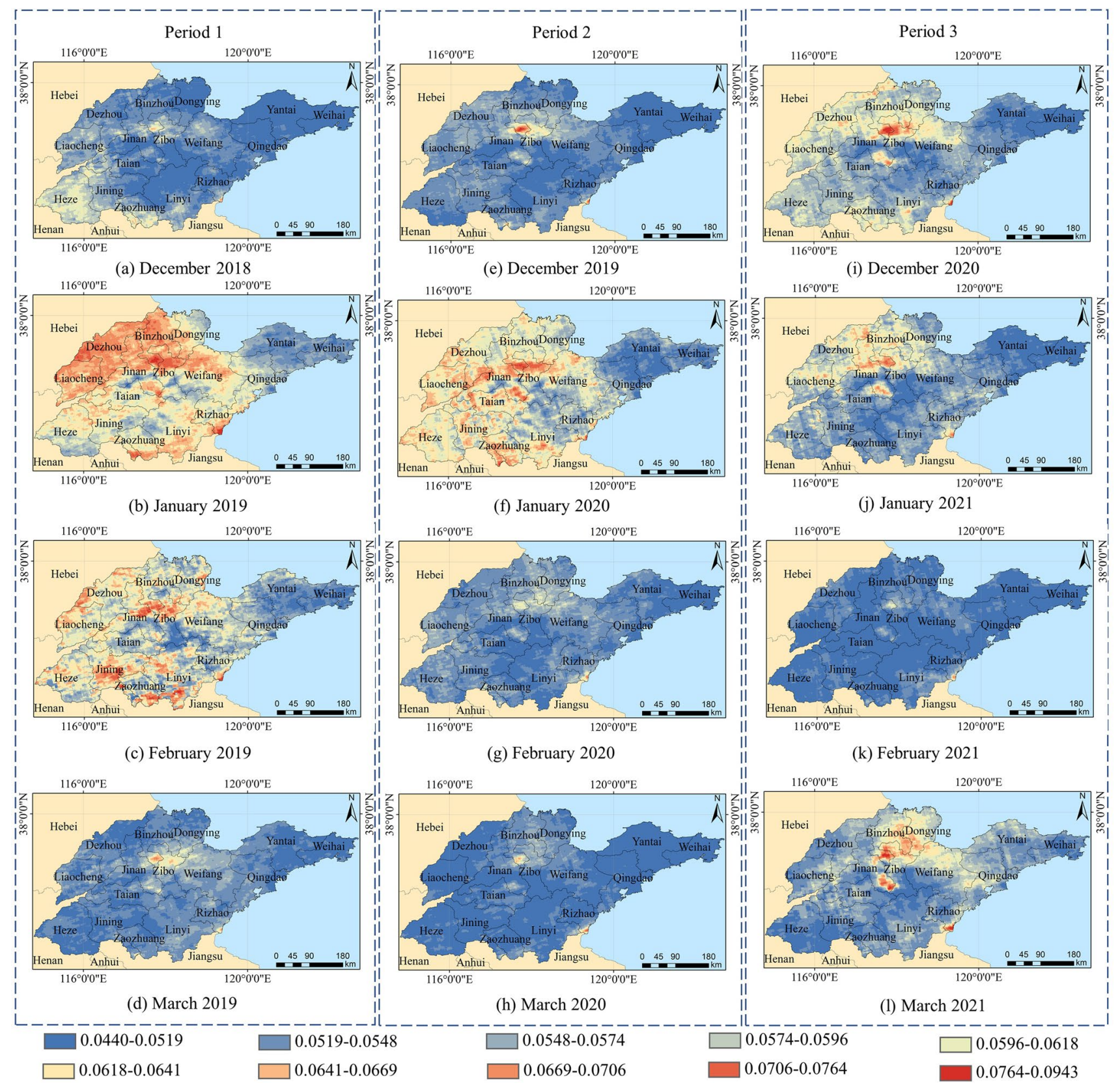

Fig. 3 Spatial distribution of CO concentration 


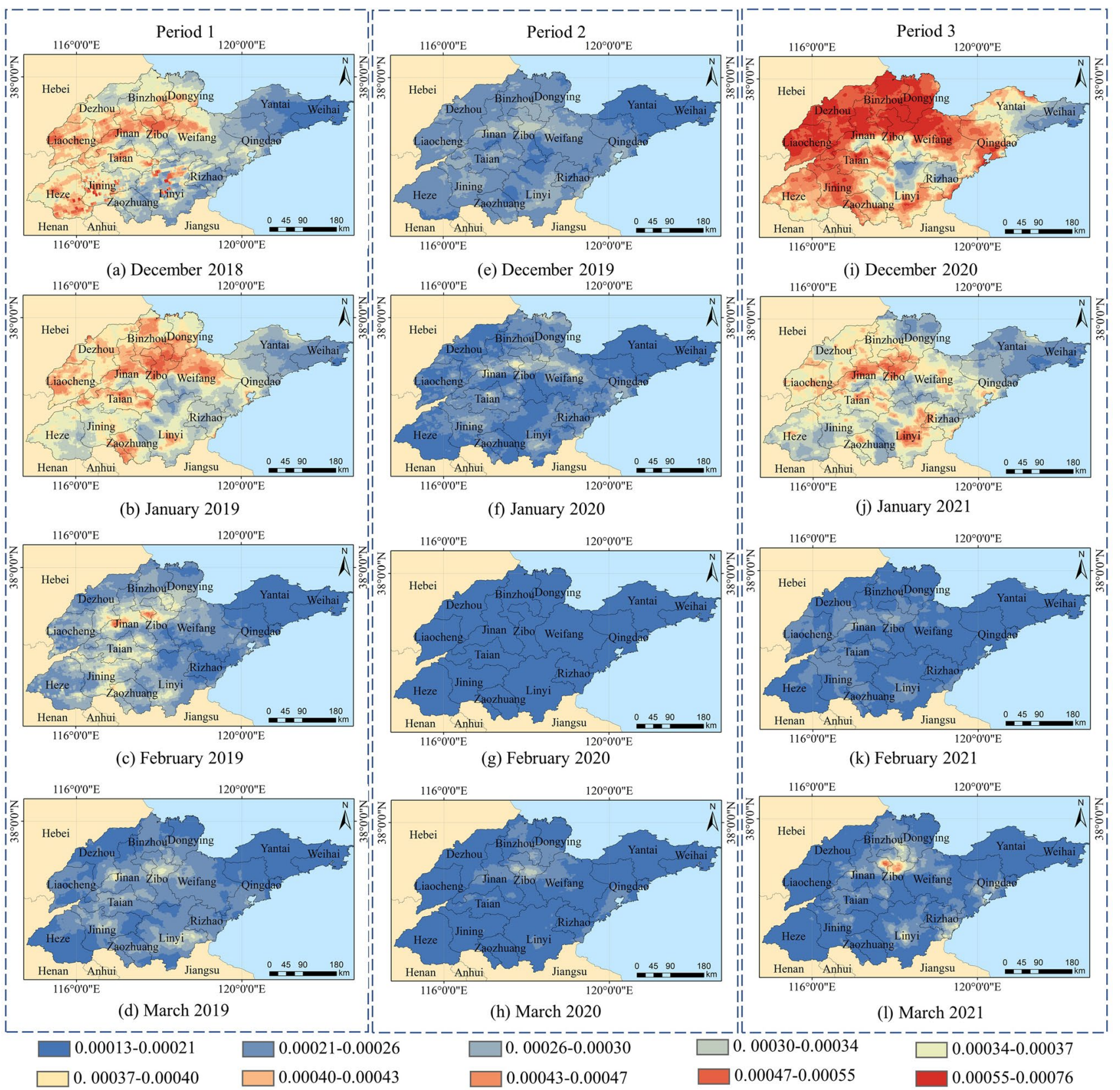

Fig. 4 Spatial distribution of $\mathrm{NO}_{2}$ concentration

January 2019 and the highest $\mathrm{NO}_{2}$ concentrations were observed in December 2020, while no significant changes were observed in $\mathrm{SO}_{2}$ concentrations. There was a more significant increase in pollutant concentrations in March 2021 compared to the same period in 2019-2020. From the annual perspective, $\mathrm{CO}$ and $\mathrm{NO}_{2}$ were significantly lower in Period 2 compared to Period 1, with an average total amount of CO decreased by $4082.36 \mathrm{~mol} / \mathrm{m}^{2}$ and an average total change rate of $4.80 \%$, an average total amount of $\mathrm{NO}_{2}$ decreased by $167.25 \mathrm{~mol} / \mathrm{m}^{2}$ and an average total change rate of $38.11 \%$. There was a significant increase between Period 2 and Period 3, with the average total amount of $\mathrm{CO}$ and $\mathrm{NO}_{2}$ increased by $730.46 \mathrm{~mol} /$ $\mathrm{m}^{2}$ and $167.93 \mathrm{~mol} / \mathrm{m}^{2}$, respectively, and the average total change rate was $0.90 \%$ and $61.84 \%$. As shown in Fig. 5, $\mathrm{SO}_{2}$ exhibited little variation over the study interval, which is somewhat related to the missing data. Comparing Period 1 and Period 2, the average total amount of $\mathrm{SO}_{2}$ increased by $72.08 \mathrm{~mol} / \mathrm{m}^{2}$ up about $10.44 \%$, and decreased by $2.41 \mathrm{~mol} / \mathrm{m}^{2}$ in Period 2 and Period 3. The central region of Shandong Province, namely Jinan City, Binzhou City and Zibo City, had high concentrations of 


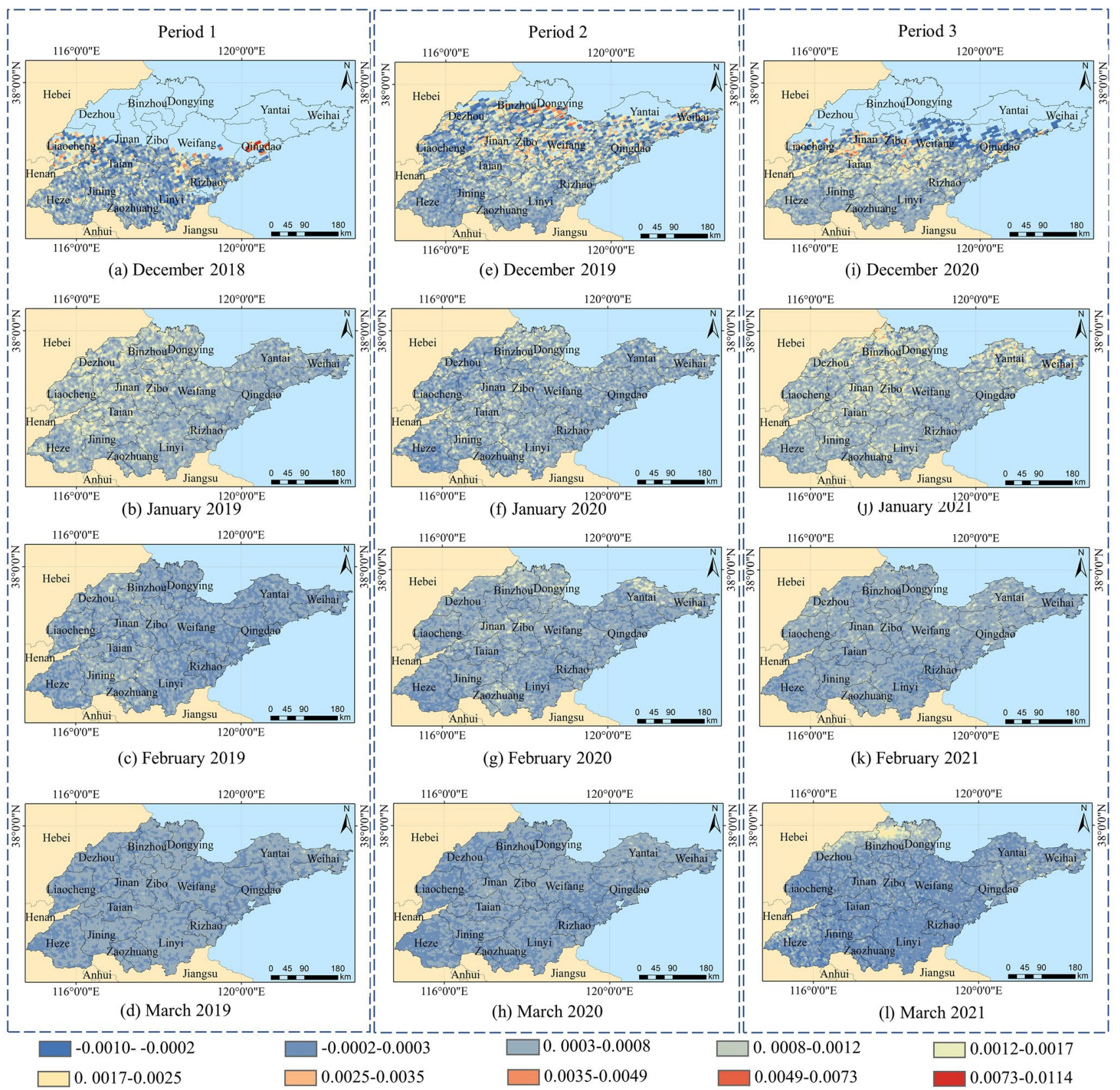

Fig. 5 Spatial distribution of $\mathrm{SO}_{2}$ concentration

pollutants in the year-round. Pollutant concentrations in the eastern coastal areas of Shandong Province such as Weihai City, Yantai City, and Qingdao City were at low levels year-round.

\section{Spatial and temporal analysis of AOD}

AOD data can also effectively reflect the ground pollution (Lee et al. 2011; Ranjan et al. 2020). As shown in Fig. 7, in Period 1-Period 2, the average total change in AOD had a significant increase of about $1.69 \times 10^{7}$, with an average total change rate of $2.54 \%$. In Period 2-Period 3, the average total amount of AOD decreased by $4.49 \times 10^{7}$, with an average total change rate of $6.58 \%$. As shown in Fig. 8, AOD in December 2019-January 2020 showed a more pronounced increase compared to December 2018 to January 2019, mainly concentrated in the western part of Shandong Province, namely Heze City, Liaocheng City, and Dezhou City. AOD in February-March 2020 presented a decreasing trend compared to the same period in 2019, and the most obvious areas were the southern regions of Shandong Province, namely Zaozhuang City, 


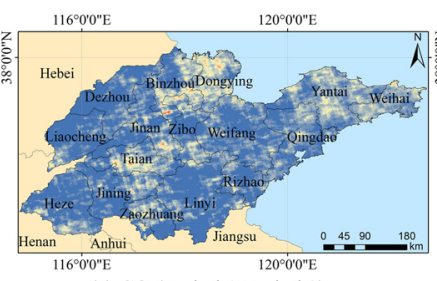

(a) $\mathrm{CO}($ Period 1-Period 2)

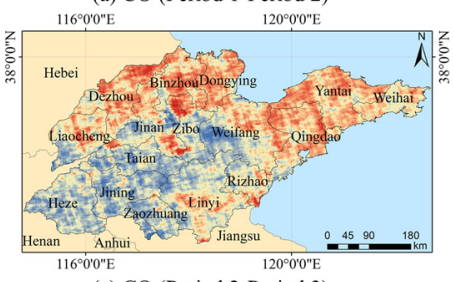

(e) CO (Period 2-Period 3)

$-0.0317-0.0119 \quad-0.0119--0.007$

$-0.0078--0.0044$

$\square-0.0011-0.002$

$0.0052-0.0083$

$0.0116-0.0166$

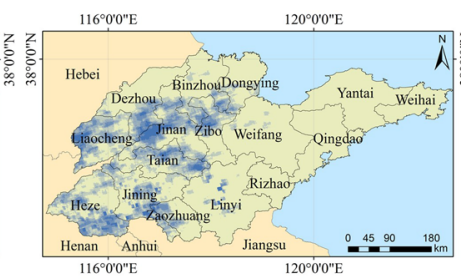

(b) $\mathrm{NO}_{2}$ (Period 1-Period 2)

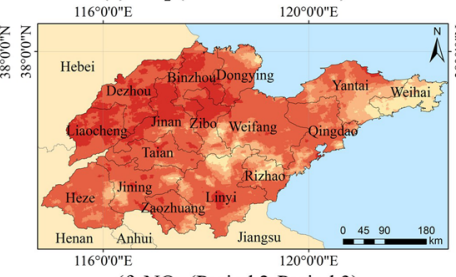

(f) $\mathrm{NO}_{2}$ (Period 2-Period 3)

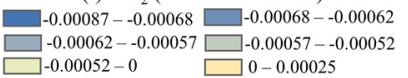

$-0.00062--0.00057 \square-0.00057--0.000$
$-0.00052-0$
$0.00025-0.00032$

$-0.00052-0 \quad \square 0-0.00025$

$0.00025-0.00032 \square$
$0.00037-0.00057$
$\square$

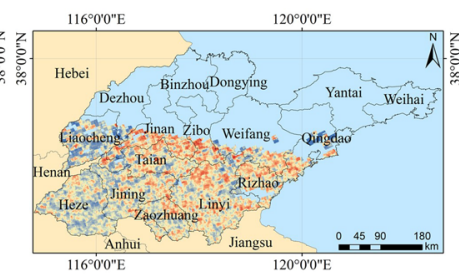

(c) $\mathrm{SO}_{2}($ Period 1-Period 2)

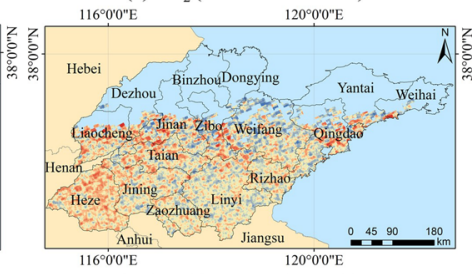

(g) $\mathrm{SO}_{2}$ (Period 2-Period 3)

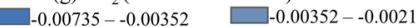

$-0.00211--0.00122 \square-0.00122--0.00058$

$-0.00058-0$

$0.00059-0.00130$

$0.00218-0.00383$

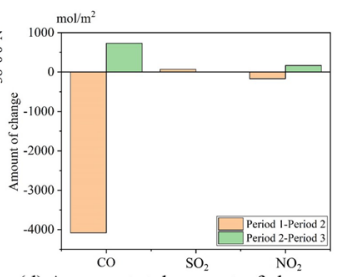

(d) Average total amount of change

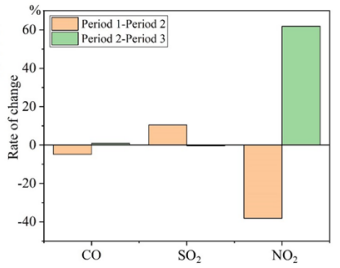

(h) Average total rate of change

Fig. 6 Spatial change of pollutants in Period 1-Period 2 and Period 2-Period 3

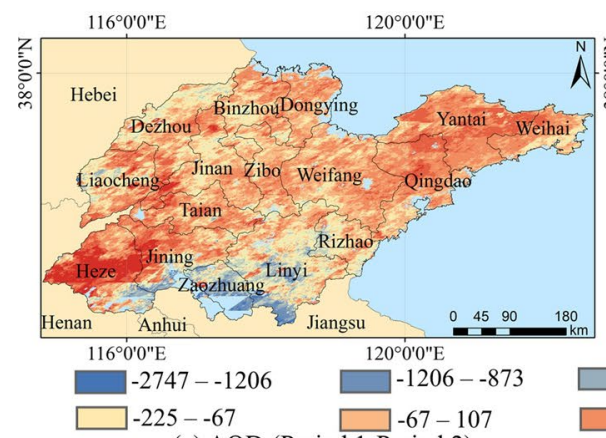

(a) AOD (Period 1-Period 2)

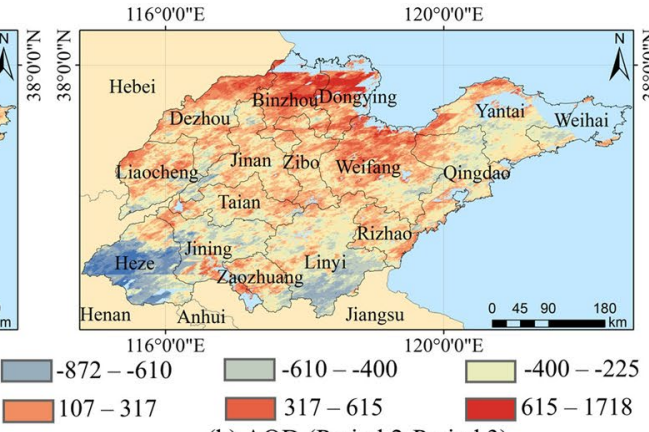

(b) AOD (Period 2-Period 3)

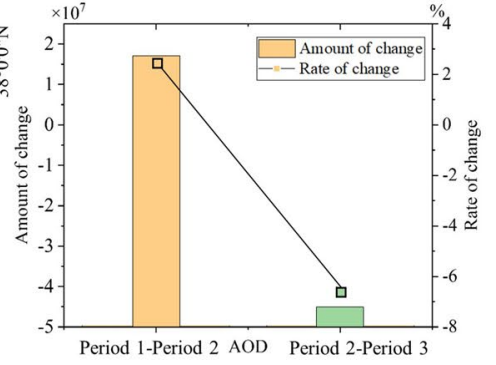

(c) Average total amount of change and average total rate of change

Fig. 7 Spatial change of AOD in Period 1-Period 2 and Period 2-Period 3

Linyi City, and Jining City. However, AOD for December 2020 to February 2021 displayed another marked decline compared to December 2019 to February 2020. AOD returned to previous levels and increased significantly in March 2021.

\section{Analysis of the driving factors in air quality changes before and after COVID-19}

Pollutant concentration changes are influenced by a combination of factors (e.g., natural factors, anthropogenic factors) (Pei et al. 2021; Sahoo 2021; Zhou et al. 2021). In order to study the driving factors of air quality changes in Shandong Province before and after the COVID-19 pandemic, meteorological data from 16 prefecture-level cities in Shandong Province were considered as natural factors data and relevant data released by the National Bureau of Statistics were taken as anthropogenic factors.

\section{Correlation analysis and regression analysis of meteorological factors and air pollutants}

The main meteorological data used to explore the correlation between meteorological data and air quality were average temperature (AT), average humidity $(\mathrm{AH})$, average wind speed (AWS), average precipitation (AP), average barometric pressure (ABP), average total cloud cover (ATCC), and average visibility (AV).

Table 2 shows the Pearson correlation coefficients between air pollutants and natural factors (i.e., meteorological data). The air pollutants were more significantly correlated with each other. $\mathrm{CO}$ had a more significant correlation with AT, AWS, ATCC, and AV. $\mathrm{NO}_{2}$ was correlated with AT, AWS, and AV. $\mathrm{SO}_{2}$ showed a correlation with AT and AV. There was a significant correlation between AOD and $\mathrm{AH}, \mathrm{AWS}, \mathrm{ATCC}$ and AV. Therefore, these meteorological factors are affecting the air quality changes to some extent. 


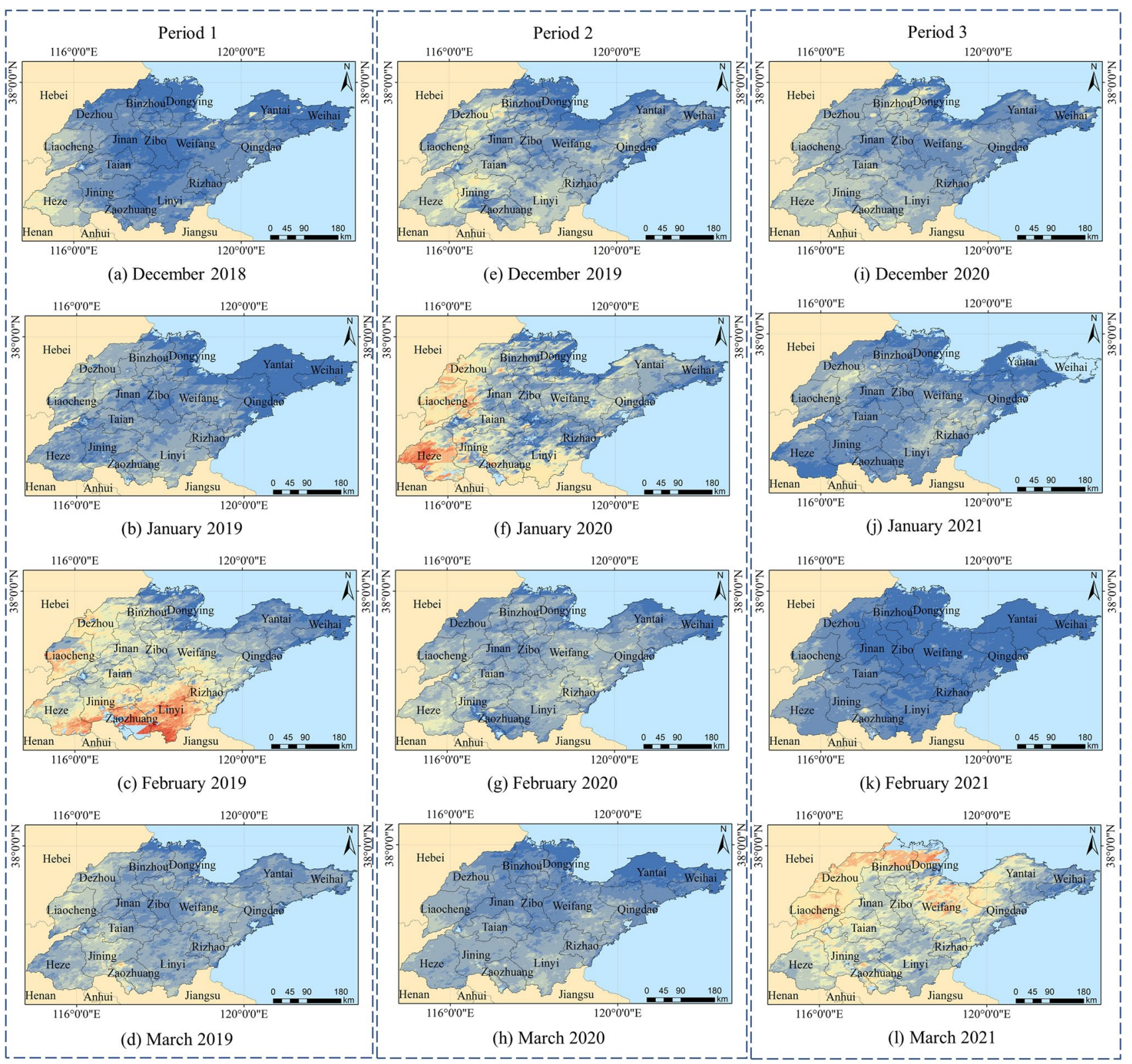

0-300 $\square 300-400 \square 400-500 \square$

500-600

600-700

$700-900$

900-1200

$1200-1500$

$1500-2000$

2000-3000

Fig. 8 Spatial distribution of AOD

As shown in Table 3, the Moran's I value for both the COmeteorological model and the $\mathrm{NO}_{2}$-meteorological model were less than 0.05 , the LM-lag values were less than 0.05 , and the LM-error values were greater than 0.05 , so the optimal CO-meteorological model and the $\mathrm{NO}_{2}$-meteorological model were SLM models. The Moran's I value for both the $\mathrm{SO}_{2}$-meteorological model and the AOD-meteorological model were greater than 0.05 , and the LM-lag and LM-error values were greater than 0.05 , thus the optimal $\mathrm{SO}_{2}$-meteorological model and the AOD-meteorological model were OLS models. The $\mathrm{R}^{2}$ values showed that the regression models of each pollutant and meteorological factors were well fitted and could provide a general reference for pollutant concentrations.

\section{Analysis of anthropogenic factors in air quality change before and after COVID-19}

The anthropogenic factors affecting air quality can be classified as industrial factors, mobile factors and domestic factors. The industrial factors were industrial value added, cement, thermal power, crude oil processing, coke, 
Table 2 Correlation analysis of air quality and meteorological factors

\begin{tabular}{|c|c|c|c|c|c|c|c|c|c|c|c|}
\hline & $\mathrm{CO}$ & $\mathrm{NO}_{2}$ & $\mathrm{SO}_{2}$ & AOD & $\mathrm{AT}$ & $\mathrm{AH}$ & AWS & $\mathrm{AP}$ & $\mathrm{ABP}$ & ATCC & $\mathrm{AV}$ \\
\hline $\mathrm{CO}$ & 1 & & & & & & & & & & \\
\hline $\mathrm{NO}_{2}$ & $0.600 * *$ & 1 & & & & & & & & & \\
\hline $\mathrm{SO}_{2}$ & 0.136 & $0.363 * *$ & 1 & & & & & & & & \\
\hline AOD & $0.408^{* *}$ & 0.084 & $-0.228 * *$ & 1 & & & & & & & \\
\hline AT & $-0.467 * *$ & $-0.572 * *$ & $-0.456 * *$ & 0.042 & 1 & & & & & & \\
\hline $\mathrm{AH}$ & 0.141 & -0.077 & 0.049 & $0.397 * *$ & $-0.224 * *$ & 1 & & & & & \\
\hline AWS & $-0.407 * *$ & $-0.254 * *$ & -0.127 & $-0.191^{*}$ & -0.071 & $-0.160 *$ & 1 & & & & \\
\hline $\mathrm{AP}$ & -0.063 & -0.115 & 0.111 & 0.031 & $-0.245^{* *}$ & $0.419 * *$ & 0.074 & 1 & & & \\
\hline $\mathrm{ABP}$ & 0.116 & 0.012 & 0.080 & -0.012 & $0.279 * *$ & $0.190^{*}$ & $-0.691 * *$ & $-0.206^{* *}$ & 1 & & \\
\hline ATCC & $0.248 * *$ & -0.004 & -0.074 & $0.376^{* *}$ & $-0.241 * *$ & $0.343 * *$ & -0.060 & $0.210 * *$ & -0.044 & 1 & \\
\hline $\mathrm{AV}$ & $-0.471 * *$ & $-0.280 * *$ & $-0.152 *$ & $-0.495 * *$ & $0.168^{*}$ & $-0.599 * *$ & $0.584 * *$ & -0.055 & $-0.378 * *$ & -0.139 & 1 \\
\hline
\end{tabular}

$* \mathrm{p}<0.05, * * \mathrm{p}<0.01$

non-ferrous metals, flat glass and crude steel. The mobile factors were gasoline, diesel, road passenger volume and road freight volume. The domestic factors were raw coal, liquefied natural gas, natural gas and gas.

Industrial activity in Shandong Province declined significantly during the outbreak and lockdown period due to the combined effects of the Chinese New Year holiday and the pandemic control. As shown in Fig. 9, the value added of industry in Shandong Province dropped significantly by $34.34 \%$ year-on-year from Period 2. Shandong Province's coke, cement, thermal power, non-ferrous metals, crude steel and other industry output year-onyear declined by $10.866 \%, 2.461 \%, 3.713 \%, 7.801 \%$ and $5.912 \%$. Crude oil processing and flat glass industry output rose year-onyear, respectively, $1.660 \%$ and $4.902 \%$. The production process of coking, steel and glass companies cannot be interrupted, so the

Table 3 Regression analysis of air quality and meteorological factors

\begin{tabular}{|c|c|c|c|c|}
\hline \multirow{3}{*}{$\begin{array}{l}\text { Variable } \\
\text { Pollutants }\end{array}$} & \multicolumn{4}{|l|}{ Coefficient } \\
\hline & \multicolumn{2}{|l|}{ SLM model } & \multicolumn{2}{|l|}{ OLS model } \\
\hline & $\mathrm{CO}$ & $\mathrm{NO}_{2}$ & $\mathrm{SO}_{2}$ & AOD \\
\hline AT & $-1.254 \times 10^{-4}$ & $-3.100 \times 10^{-7}$ & $-2.824 \times 10^{-5}$ & 26.615 \\
\hline $\mathrm{AH}$ & $6.825 \times 10^{-5}$ & $3.080 \times 10^{-6}$ & $3.759 \times 10^{-6}$ & -2.751 \\
\hline AWS & $-7.259 \times 10^{-4}$ & $-2.630 \times 10^{-5}$ & $-4.964 \times 10^{-5}$ & 26.583 \\
\hline $\mathrm{AP}$ & $-1.814 \times 10^{-4}$ & $-3.166 \times 10^{-6}$ & $-1.734 \times 10^{-5}$ & -0.438 \\
\hline $\mathrm{ABP}$ & $-1.315 \times 10^{-5}$ & $-8.333 \times 10^{-7}$ & $-4.933 \times 10^{-7}$ & -1.277 \\
\hline ATCC & $-4.473 \times 10^{-6}$ & $-6.509 \times 10^{-7}$ & $-1.604 \times 10^{-6}$ & 3.412 \\
\hline AV & $6.896 \times 10^{-5}$ & $5.553 \times 10^{-6}$ & $2.555 \times 10^{-5}$ & -23.557 \\
\hline $\begin{array}{l}\text { Constant inter- } \\
\text { cept }\end{array}$ & 0.033 & $7.953 \times 10^{-4}$ & 0.001 & 1871.12 \\
\hline$\rho$ & 0.633 & 0.710 & - & - \\
\hline $\mathrm{R}^{2}$ & 0.899 & 0.906 & 0.699 & 0.905 \\
\hline Moran’s I & 0.004 & 0.001 & 1 & 0.606 \\
\hline LM-lag & 0.037 & 0.029 & 0.653 & 0.265 \\
\hline LM-error & 0.316 & 0.129 & 0.425 & 0.498 \\
\hline
\end{tabular}

actual pollution emissions from these industries do not change much (Zhu et al. 2021). As a result, pollution from different industrial sectors has different impacts on air quality.

Mobile source emissions also showed a significant decline. Figure 9 shows that the national road passenger volume decreased by $59.370 \%$ year-on-year from Period 2. The national road freight volume increased by $1.810 \%$ yearon-year. Shandong Province is in the vicinity of the capital economic circle and has a large volume of cargo transportation. The output of gasoline and diesel products in Shandong Province dropped $24.954 \%$ and $12.872 \%$ year-on-year, respectively. According to changes in $\mathrm{NO}_{2}$ concentrations, there was a significant decrease in emissions from road motor vehicles and a significant reduction in other mobile sources.

Emissions from domestic sources increased somewhat. Liquefied natural gas and gas in Shandong Province increased by $71.875 \%$ and $7.351 \%$ respectively compared to the same period. Raw coal and natural gas in Shandong Province decreased by $2.258 \%$ and $12.500 \%$, respectively. The increase in the amount of gas used by residents in Shandong Province made an important contribution to air pollution. Moreover, the heating season in the cities extended by about 2 weeks, with a corresponding increase in pollutant emissions caused by residential heating, which will have a certain negative impact on the air quality (Zhu et al. 2021).

\section{Discussion}

\section{Analysis of the causes in air quality changes before and after COVID-19}

Based on the above results, it can be noted that $\mathrm{CO}$ and $\mathrm{NO}_{2}$ decreased significantly during the outbreak and lockdown period compared to the same period, and $\mathrm{SO}_{2}$ did not change significantly. It is worth noting that the sources of $\mathrm{CO}$ are mainly 
Fig. 9 The change in air quality, industrial sources, mobile sources and domestic sources from Period 2 compared to the same period in Period 1

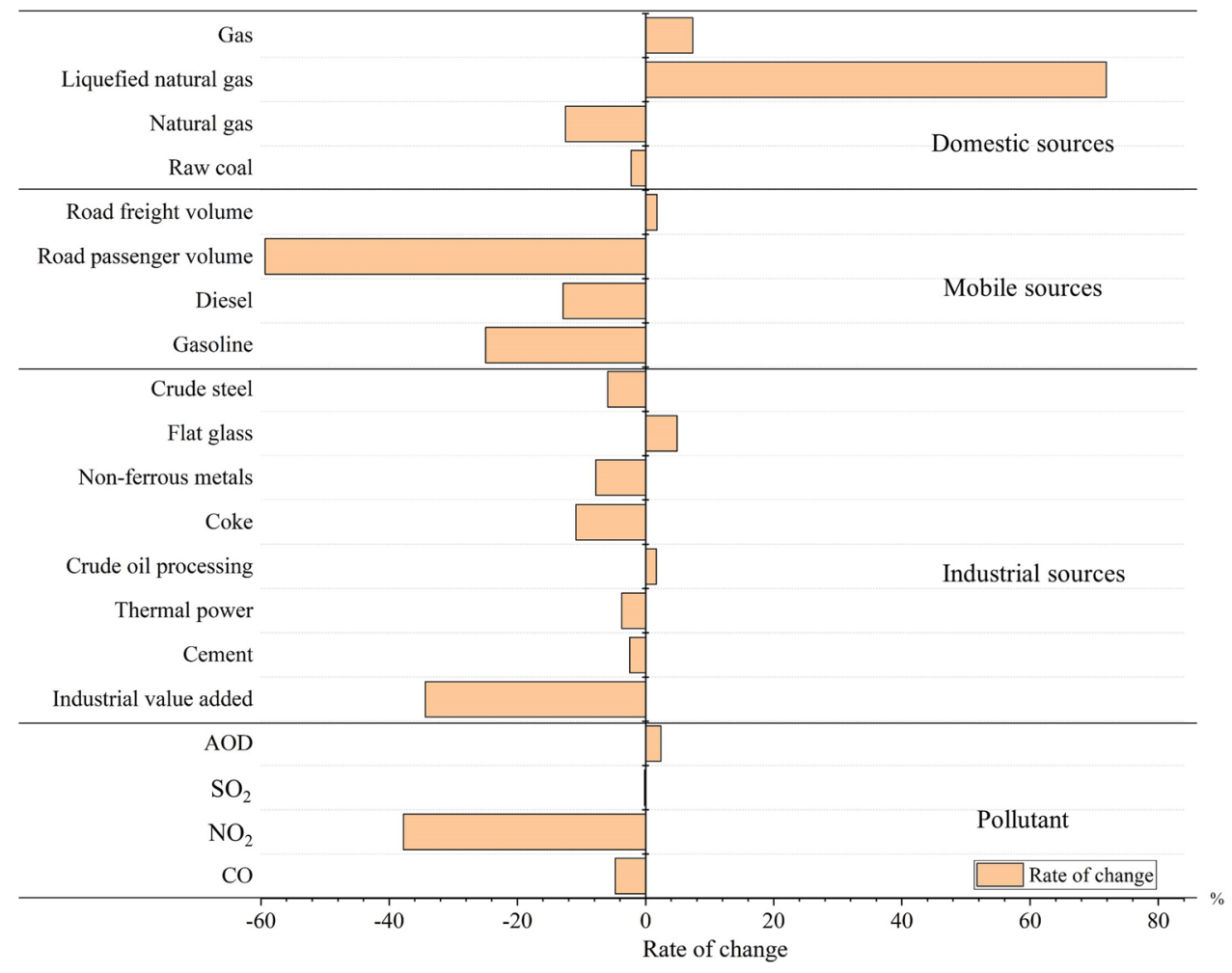

incomplete combustion of fossil fuels and motor vehicle exhaust emissions (Kang et al. 2019). $\mathrm{NO}_{2}$ comes mainly from vehicle exhaust, fuel combustion in industry and industrial production processes of nitric acid, nitrogen fertilizer and explosives, as well as lightning (Yu et al. 2020). $\mathrm{SO}_{2}$ mostly originates from the smelting of sulfur-containing ores, the burning of fossil fuels, or industrial emissions from sulfuric acid and phosphate fertilizer production (Torbatian et al. 2020). Human travel activities and production operations have been greatly reduced due to pandemics and home quarantine policies, thereby resulting in a reduction in $\mathrm{CO}$ and $\mathrm{NO}_{2}$ (Yang et al. 2018; Copat et al. 2020).

AOD had a significant increase in January 2020. Combining the relevant literature, the reasons for the increase in AOD may be as follows: the reduction of pollutants like $\mathrm{NO}_{\mathrm{x}}$ leads to an increase in ozone formation, which enhances the oxidation capacity of the atmosphere and promotes condensation around existing or new particles, leading to the production of particulate compounds (e.g., sulfates, nitrates, and organic compounds) (Huang et al. 2020; Nichol et al. 2020). Figure 10 shows the comparison of meteorological data (i.e., AT, AH, ABP, and AWS) for some typical cities in December-March. Meteorological data during the lockdown period varied within acceptable ranges from contemporaneous data. However, the typical city had greater AH from December 2019 to February 2020 than during the same period. Higher AH also promotes the formation of particulate compounds. These particulate compounds are less absorbed in nature and prone to form $\mathrm{PM}_{2.5}$, which in turn also leads to an increase in AOD (Zhao et al. 2019; Wang et al. 2020; Zhang et al. 2020). On the other hand, urban heating in winter is also responsible for the increase in AOD.

\section{Implications and recommendations of air quality change research}

This study is important for understanding the current status of air quality qualitatively and quantitatively, and exploring the extent of natural and anthropogenic factors influencing air quality changes. It is significant for informing decisions on relevant policies to achieve the ultimate goal of improving air quality. From the perspective of anthropogenic factors, controlling anthropogenic emissions (especially industrial and mobile sources) is a fundamental measure to improve air quality. Natural factors (i.e., meteorological factors) have a strong correlation with air quality, and air quality-meteorological models have a good fit. Therefore, relevant departments can combine the air quality spatial and temporal distribution maps to selectively regulate and block the local areas with high pollutant concentrations (e.g., Zibo City, Binzhou City, and Jinan City) in making relevant government decisions. On this basis, it is necessary to understand meteorological information of cities with air pollution sources and design a reasonable industrial production layout and effective environmental planning. Then, it is desirable to change the energy structure and promote the use of clean fuels and clean production processes, thereby reducing pollutant emissions. 


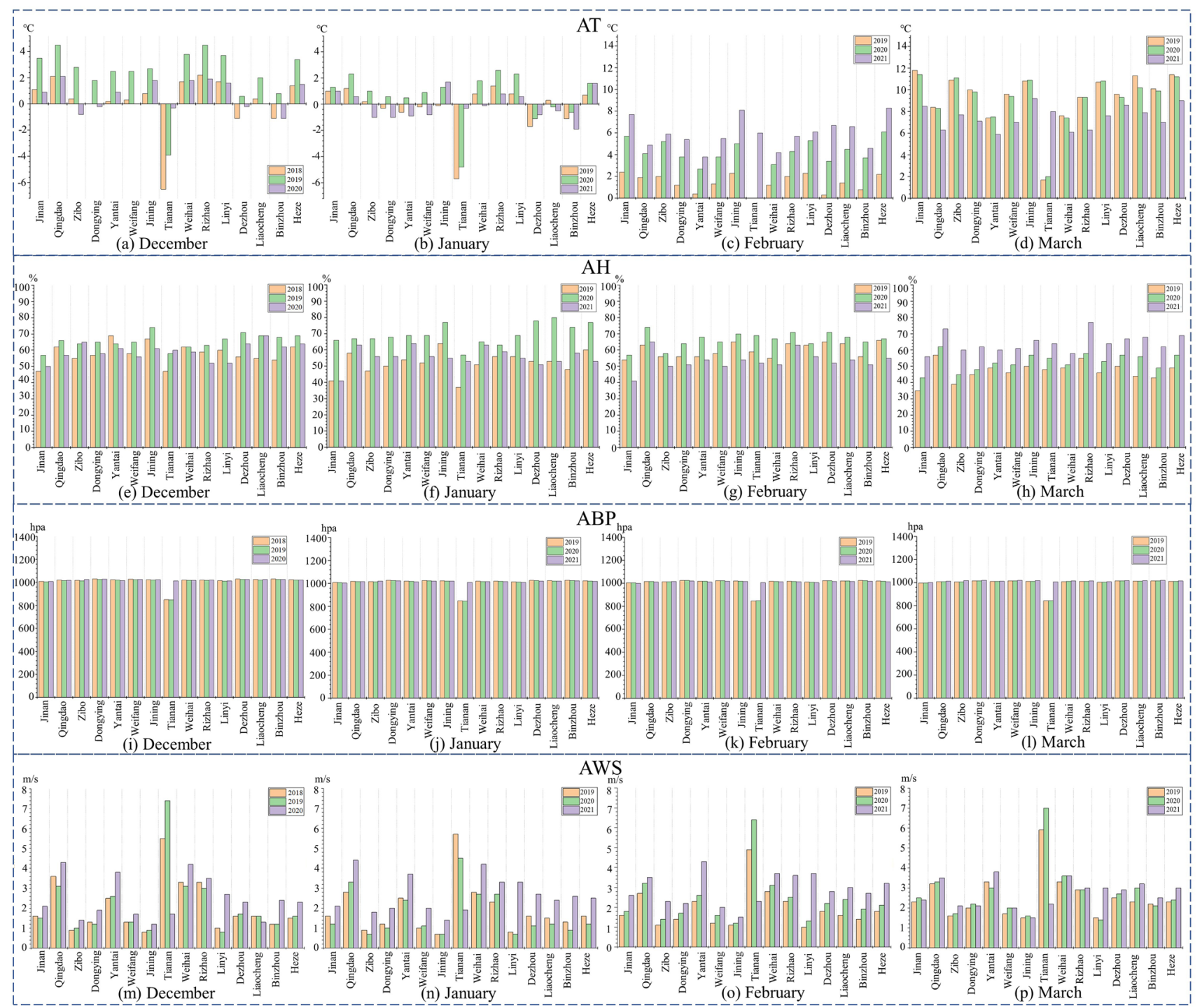

Fig. 10 Comparison of meteorological factors

This study has certain implications for remote sensing image data to conduct atmospheric monitoring studies. It demonstrates to some extent the usefulness of using the GEE platform to obtain Sentinel-5P data for spatial and temporal analysis in air pollution at different regional scales (Schneider et al. 2021). First, Sentinel-5P data is a free, high spatial resolution product that provides offline and near realtime air pollution data. Second, compared to ground-based air quality stations that provide only punctual information, Sentinel-5P data is a continuous data surface with daily global coverage. It grids a large amount of spatial data and is able to present the spatial distribution of different pollutants at a given time. However, there are some problems with Sentinel-5P data, such as cloud coverage and limitations in the number of observations, which hinder exhaustive air pollution monitoring (Vîrghileanu et al. 2020).

\section{Conclusions}

In this paper, pollutant concentrations and AOD data in Shandong Province were obtained from December 2018March 2019, December 2019-March 2020, and December 2020-March 2021 using the GEE cloud platform. The spatial and temporal distributions of air quality changes in Shandong Province before and after the COVID-19 pandemic were studied, and the reasons for the changes were analyzed. Specific conclusions are presented below.

(1) Shandong Province had the highest $\mathrm{CO}$ concentration in January 2019 and the highest $\mathrm{NO}_{2}$ concentration in December 2020, while $\mathrm{SO}_{2}$ concentration did not change significantly. A significant increase in AOD existed in Period 2. Pollutant concentrations increased 
more significantly in March 2021 compared to the same period in 2019-2020.

(2) Compared with Period 1, the average total amount of $\mathrm{CO}$ and $\mathrm{NO}_{2}$ decreased by $4082.36 \mathrm{~mol} / \mathrm{m}^{2}$ and $167.25 \mathrm{~mol} / \mathrm{m}^{2}$ in Period 2, with an average total change rate of $4.80 \%$ and $38.11 \%$, respectively. Between Period 2-Period 3, the average total amount of $\mathrm{CO}$ and $\mathrm{NO}_{2}$ increased by $730.46 \mathrm{~mol} / \mathrm{m}^{2}$ and $167.93 \mathrm{~mol} /$ $\mathrm{m}^{2}$, respectively, with the average total change rate of $0.90 \%$ and $61.84 \%$. The average total amount of $\mathrm{SO}_{2}$ and AOD increased by $72.08 \mathrm{~mol} / \mathrm{m}^{2}$ and $1.69 \times 10^{7}$ up about $10.44 \%$ and $2.54 \%$ between Period 1-Period 2 , respectively, while decreased by $2.41 \mathrm{~mol} / \mathrm{m}^{2}$ and $4.49 \times 10^{7}$ in Period 2-Period 3.

(3) Pollutant concentrations show significant correlation with meteorological data. $\mathrm{CO}$ was significantly related to AT, AWS, ATCC and AV, $\mathrm{NO}_{2}$ was relevant to AT, AWS and AV. $\mathrm{SO}_{2}$ was correlated with $\mathrm{AT}$ and $\mathrm{AV}$, and $\mathrm{AOD}$ was significantly associated with AH, AWS, ATCC and AV.

(4) The significant decrease in $\mathrm{CO}$ and $\mathrm{NO}_{2}$ from December 2019-March 2020 compared to the same period was mainly due to the reduction in human travel activities and production operations. AOD showed an increasing trend during January 2020, which was associated with urban heating and decreases in pollutants such as $\mathrm{NO}_{\mathrm{x}}$.

The GEE platform can help more countries and regions to understand the spatial and temporal changes of air quality and offer the theoretical basis for the management and protection of atmospheric environmental quality. In the future, air quality changes will be studied in a larger study area.

Acknowledgements This paper is jointly funded by the National Natural Science Foundation of China (41801308, and 41930107); Open Fund of State Laboratory of Information Engineering in Surveying, Mapping and Remote Sensing, Wuhan University (20S01); Doctoral Research Fund of Shandong Jianzhu University (XNBS1804), Key Laboratory of Land Satellite Remote Sensing Application Center, Ministry of Natural Resources of the People's Republic of China and Science and Technology Support Program for Youth Innovation in Colleges and Universities of Shandong Province (2019KJG005). The authors would like to thank the editors and the anonymous reviewers for their constructive comments and suggestions, which greatly helped to improve the quality of the manuscript.

\section{References}

Asokan A, Anitha J (2019) Change detection techniques for remote sensing applications: a survey. Earth Sci Inform 12:1-18. https:// doi.org/10.1007/s12145-019-00380-5

Azuma K, Kagi N, Kim H, Hayashi M (2020) Impact of climate and ambient air pollution on the epidemic growth during COVID-19 outbreak in Japan. Environ Res 190:110042. https://doi.org/10. 1016/j.envres.2020.110042
Baeza S, Paruelo JM (2020) Land use/land cover change (2000-2014) in the rio de la plata grasslands: An analysis based on MODIS NDVI time series. Remote Sens 12:1-22. https://doi.org/10.3390/ rs 12030381

Butz A, Galli A, Hasekamp O et al (2012) TROPOMI aboard Sentinel-5 Precursor: Prospective performance of $\mathrm{CH} 4$ retrievals for aerosol and cirrus loaded atmospheres. Remote Sens Environ 120:267-276. https://doi.org/10.1016/j.rse.2011.05.030

Chen A, Yang X, Xu B et al (2021) Monitoring the spatiotemporal dynamics of aeolian desertification using google earth engine. Remote Sens 13. https://doi.org/10.3390/rs13091730

Copat C, Cristaldi A, Fiore M et al (2020) The role of air pollution (PM and NO2) in COVID-19 spread and lethality: A systematic review. Environ Res 191:110129. https://doi.org/10.1016/j. envres.2020.110129

Dlamini LZD, Xulu S (2019) Monitoring mining disturbance and restoration over RBM site in South Africa using landtrendr algorithm and landsat data. Sustainability 11. https://doi.org/ 10.3390/SU11246916

Dutheil F, Baker JS, Navel V (2020) COVID-19 as a factor influencing air pollution? Environ Pollut 263:2019-2021. https://doi. org/10.1016/j.envpol.2020.114466

Ghasempour F, Sekertekin A, Kutoglu SH (2021) Google Earth Engine based spatio-temporal analysis of air pollutants before and during the first wave COVID-19 outbreak over Turkey via remote sensing. J Clean Prod 128599. https://doi.org/10.1016/J. JCLEPRO.2021.128599

Gorelick N, Hancher M, Dixon M et al (2017) Google Earth Engine: Planetary-scale geospatial analysis for everyone. Remote Sens Environ 202:18-27. https://doi.org/10.1016/j.rse.2017.06.031

$\mathrm{Hu}$ Y, Dong Y, Batunacun (2018) An automatic approach for landchange detection and land updates based on integrated NDVI timing analysis and the CVAPS method with GEE support. ISPRS J Photogramm Remote Sens 146:347-359. https://doi. org/10.1016/j.isprsjprs.2018.10.008

Huang X, Ding A, Gao J et al (2020) Enhanced secondary pollution offset reduction of primary emissions during COVID-19 lockdown in China. Natl Sci Rev. https://doi.org/10.1093/nsr/ nwaa137

Kang H, Zhu B, van der A RJ et al (2019) Natural and anthropogenic contributions to long-term variations of $\mathrm{SO} 2, \mathrm{NO} 2, \mathrm{CO}$, and AOD over East China. Atmos Res 215:284-293. https://doi.org/ 10.1016/j.atmosres.2018.09.012

Lee HJ, Liu Y, Coull BA et al (2011) A novel calibration approach of MODIS AOD data to predict PM2.5 concentrations. Atmos Chem Phys 11:7991-8002. https://doi.org/10.5194/acp-11-7991-2011

Lina Z, Lixun L (2019) Spatial distribution and format difference of large-scale retail business facilities: a case study of Guangzhou based on POI data. Trop Grography 39:88-100

Liu Y, Long H, Li T, Tu S (2015) Land use transitions and their effects on water environment in Huang-Huai-Hai Plain, China. Land use policy 47:293-301. https://doi.org/10.1016/j.landusepol.2015.04. 023

Mandal D, Kumar V, Bhattacharya A et al (2018) Sen4Rice: A processing chain for differentiating early and late transplanted rice using time-series sentinel-1 SAR data with google earth engine. IEEE Geosci Remote Sens Lett 15:1947-1951. https://doi.org/10.1109/ LGRS.2018.2865816

Meng Y, Wong MS, Xing $\mathrm{H}$ et al (2021) Yearly and daily relationship assessment between air pollution and early-stage covid-19 incidence: evidence from 231 countries and regions. ISPRS Int J Geo-Information 10:1-16. https://doi.org/10.3390/ijgi10060401

Mollalo A, Vahedi B, Rivera KM (2020) GIS-based spatial modeling of COVID-19 incidence rate in the continental United States. Sci Total Environ 728:138884. https://doi.org/10.1016/j.scitotenv. 2020.138884 
Nichol JE, Bilal M, Ali AM, Qiu Z (2020) Air pollution scenario over China during COVID-19. Remote Sens 12. https://doi.org/10. 3390/rs12132100

Özelkan E (2020) Water body detection analysis using NDWI indices derived from landsat-8 OLI. Polish J Environ Stud 29:1759-1769. https://doi.org/10.15244/pjoes/110447

Pei L, Wang X, Guo B et al (2021) Do air pollutants as well as meteorological factors impact Corona Virus Disease 2019 (COVID-19)? Evidence from China based on the geographical perspective. Environ Sci Pollut Res. https://doi.org/10.1007/s11356-021-12934-6

Prakash S, Goswami M, Khan YDI, Nautiyal S (2021) Environmental impact of COVID-19 led lockdown: A satellite data-based assessment of air quality in Indian megacities. Urban Clim 38:100900. https://doi.org/10.1016/j.uclim.2021.100900

Ranjan AK, Patra AK, Gorai AK (2020) Effect of lockdown due to SARS COVID-19 on aerosol optical depth (AOD) over urban and mining regions in India. Sci Total Environ 745:141024. https:// doi.org/10.1016/j.scitotenv.2020.141024

Sahoo MM (2021) Significance between air pollutants, meteorological factors, and COVID-19 infections: probable evidences in India. Environ Sci Pollut Res. https://doi.org/10.1007/ s11356-021-12709-z

Schneider P, Hamer PD, Kylling A et al (2021) Spatiotemporal patterns in data availability of the sentinel-5p no2 product over urban areas in Norway. Remote Sens 13. https://doi.org/10.3390/rs13112095

Shi Y, Shi Y (2020) Spatio-temporal variation characteristics and driving forces of farmland shrinkage in four metropolises in East Asia. Sustainability 12:1-26. https://doi.org/10.3390/su12030754

Song H, Zhuo H, Fu S, Ren L (2021) Air pollution characteristics, health risks, and source analysis in Shanxi Province, China. Environ Geochem Health 43:391-405. https://doi.org/10.1007/ s10653-020-00723-y

Tamiminia H, Salehi B, Mahdianpari M et al (2020) Google Earth Engine for geo-big data applications: A meta-analysis and systematic review. ISPRS J Photogramm Remote Sens 164:152-170. https://doi.org/10.1016/j.isprsjprs.2020.04.001

Torbatian S, Hoshyaripour A, Shahbazi H, Hosseini V (2020) Air pollution trends in Tehran and their anthropogenic drivers. Atmos Pollut Res 11:429-442. https://doi.org/10.1016/j.apr.2019.11.015

Vîrghileanu M, Săvulescu I, Mihai BA et al (2020) Nitrogen dioxide (No2) pollution monitoring with sentinel-5p satellite imagery over europe during the coronavirus pandemic outbreak. Remote Sens 12:1-29. https://doi.org/10.3390/rs12213575

Wang L, Yu Y, Huang K et al (2020) The inharmonious mechanism of $\mathrm{CO} 2, \mathrm{NOx}, \mathrm{SO} 2$, and $\mathrm{PM} 2.5$ electric vehicle emission reductions in Northern China. J Environ Manage 274. https://doi.org/ 10.1016/j.jenvman.2020.111236

Xu W, Liu L, Cheng M et al (2018) Spatial-temporal patterns of inorganic nitrogen air concentrations and deposition in eastern China. Atmos Chem Phys 18:10931-10954. https://doi.org/10.5194/ acp-18-10931-2018
Yang G, Huang J, Li X (2018) Mining sequential patterns of PM2.5 pollution in three zones in China. J Clean Prod 170:388-398. https://doi.org/10.1016/j.jclepro.2017.09.162

Yao Y, Pan J, Wang W et al (2020) Association of particulate matter pollution and case fatality rate of COVID-19 in 49 Chinese cities. Sci Total Environ 741:140396. https://doi.org/10.1016/j.scitotenv. 2020.140396

Yu H, Feng J, Su X et al (2020) A seriously air pollution area affected by anthropogenic in the central China: temporal-spatial distribution and potential sources. Environ Geochem Health 42:31993211. https://doi.org/10.1007/s10653-020-00558-7

Zhang B, Yin L, Zhang S, Feng C (2016) Assessment on characteristics of LUCC process based on complex network in Modern Yellow River Delta, Shandong Province of China. Earth Sci Informatics 9:83-93. https://doi.org/10.1007/s12145-015-0234-2

Zhang Y, Shen Z, Zhang B et al (2020) Emission reduction effect on $\mathrm{PM} 2.5, \mathrm{SO} 2$ and NOx by using red mud as additive in clean coal briquetting. Atmos Environ 223:117203. https://doi.org/10.1016/j. atmosenv.2019.117203

Zhao S, Wang Q, Li Y et al (2017) An overview of satellite remote sensing technology used in China's environmental protection. Earth Sci Inform 10:137-148. https://doi.org/10.1007/ s12145-017-0286-6

Zhao X, Zhou W, Han L, Locke D (2019) Spatiotemporal variation in PM2.5 concentrations and their relationship with socioeconomic factors in China's major cities. Environ Int 133:105145. https:// doi.org/10.1016/j.envint.2019.105145

Zheng Z, Yang Z, Wu Z, Marinello F (2019) Spatial variation of NO2 and its impact factors in China: An application of sentinel-5P products. Remote Sens 11:1-24. https://doi.org/10.3390/rs111 61939

Zhou X, Tong W, Li L (2020) Deep learning spatiotemporal air pollution data in China using data fusion. Earth Sci Inform 13:859 868. https://doi.org/10.1007/s12145-020-00470-9

Zhou J, Qin L, Meng X, Liu N (2021) The interactive effects of ambient air pollutants-meteorological factors on confirmed cases of COVID-19 in 120 Chinese cities. Environ Sci Pollut Res. https:// doi.org/10.1007/s11356-021-12648-9

Zhu Y, Xie J, Huang F, Cao L (2020) Association between short-term exposure to air pollution and COVID-19 infection: Evidence from China. Sci Total Environ 727:138704. https://doi.org/10.1016/j. scitotenv.2020.138704

Zhu Y, Wang W, Gao Y et al (2021) Assessment of emission reduction effect in Beijing, Tianjin and surrounding 26 cities from January to March in 2020 during the epidemic of COVID-19. China Environ Sci 41:505-516. https://doi.org/10.19674/j.cnki.issn1 000-6923.2021.0057

Publisher's Note Springer Nature remains neutral with regard to jurisdictional claims in published maps and institutional affiliations. 